\title{
Self-control: An integrative framework
}

\author{
Kaitlyn M. Werner \\ University of Toronto \\ University of Pennsylvania
}

\author{
Brett Q. Ford \\ University of Toronto
}

\begin{abstract}
Research on self-control has flourished within the last two decades, with many researchers trying to answer one of the most fundamental questions regarding human behaviour - how do we successfully regulate desires in the pursuit of long-term goals? While recent research has focused on different strategies to enhance self-control success, we still know very little about how strategies are implemented or where the need for self-control comes from in the first place. Drawing from parallel fields (e.g., emotion regulation, health) and other theories of self-regulation, we propose an integrative framework that describes self-control as a dynamic, multi-stage process that unfolds over time. In this review, we first provide an overview of this framework, which poses three stages of regulation: the identification of the need for self-control, the selection of strategies to regulate temptations, and the implementation of chosen strategies. These regulatory stages are then flexibly monitored over time. We then expand this framework by outlining a series of growth points to guide future research. By bridging across theories and disciplines, the present framework improves our understanding of how self-control unfolds in everyday life.
\end{abstract}

Keywords: self-control, strategies, regulatory flexibility, self-regulation; goal pursuit

\section{Accepted at Social and Personality Psychology Compass}

This paper is not the copy of record and may not exactly replicate the authoritative document published in Social and Personality Psychology Compass. The final article will be made available upon publication at [DOI forthcoming]

\begin{abstract}
Everybody is eager to understand self-control. From Plato's Phaedrus to modern-day conceptualizations of willpower, the concept of selfcontrol has been a core interest in understanding the human condition for millennia. This is no surprise given the profound impact of self-control, the process of resolving conflict between conflicting goals (Inzlicht et al., 2021): by being able to master our thoughts, emotions, and behaviours, we are less likely to fall victim to our vices and instead live a happier, healthier life where we thrive in our daily pursuits (Mischel et al., 1988; Moffitt et al., 2011; Roberts et al., 2014; Tangney et al., 2004). However, as anyone who has tried to pursue a goal knows, self-control is not always successful - we eat the cookie despite our goal to lose
\end{abstract}

Correspondence concerning this manuscript should be addressed to Kaitlyn M. Werner, Email: kaitlyn.werner@utoronto.ca

Funding: The preparation of this manuscript was supported by a Banting Postdoctoral Research Fellowship from the Social Sciences and Humanities Research Council (SSHRC) of Canada and a Postdoctoral Fellowship from the University of Toronto Scarborough awarded to KMW.

Acknowledgements: The authors would like to thank James Gross, Jennifer Stellar, and members of the Toronto Emotion Labs for their feedback on initial drafts of these ideas. weight, hit the snooze button on our morning alarm instead of going to the gym, or continue to buy expensive lattes which hinder our ability to save for retirement. While seemingly innocuous in the moment (e.g., "it's just one missed workout" or "it's only five dollars"), self-control failures can be quite costly at the individual and societal levels. For example, our increasingly sedentary lifestyle generates an estimated $\$ 117$ billion annually in healthcare costs (National Center for Chronic Disease Prevention and Health Promotion, 2019), and Americans are drowning in more consumer debt than ever before, reaching nearly $\$ 1$ trillion in credit card debt alone (Federal Reserve Bank of New York, 2020). Given the pervasive impact of these behaviours, it is clear why researchers, policymakers, and laypeople alike are all eager to understand how to improve self-control.

While research on self-control has grown dramatically in the last two decades, research has largely focused on explaining self-control failure and promoting the use of willpower (Baumeister, 2002; Baumeister et al., 2007; Mischel et al., 1988, 1989) that is, if we learn how to just say "no" to temptations, 
we will be more successful. However, recent theorizing argues that willpower is overrated (Inzlicht \& Friese, 2020) and so ill-defined that asking a person to "use willpower" is akin to "telling a person to build a house with a pile of wood" (Fujita et al., 2020, p. 7; see also Werner et al., 2022). Fortunately, with increasing recognition of the conceptual and practical limitations of willpower, research has turned to other more tractable strategies that people can use to pursue their goals (Duckworth et al., 2018; Hennecke et al., 2019; Hofmann \& Kotabe, 2012). While this shift to moving beyond willpower is certainly encouraging, focusing on the effectiveness of different strategies still only tells part of the story.

Building on these venerable foundations, we propose the field is ready for a new generation of research that fully embraces the complexity of selfcontrol in everyday life. To help push the field forward, our aim is to synthesize recent advances in self-control while also integrating across a range of theoretical perspectives. To achieve this objective, we propose an integrative theoretical framework - the extended process model of self-control - that describes selfcontrol as a dynamic, multi-stage process that unfolds over time. To help organize this review, we start by adapting the process model of emotion regulation (Gross, 2015) to self-control. This framework provides a conceptual scaffold that allows us to then integrate across different models of self-regulation (e.g., from social, personality, health, neuroscience, economics) as we describe each stage of the self-control process. Finally, leveraging this framework, we outline a series of exciting growth points to guide future research.

\section{Extending the Process Model of Self-Control}

The ways in which people can regulate temptations and desires are vast - so much so that the array of existing self-control strategies has been described as "dizzying in both number and variety" (Duckworth et al., 2016, p. 38). This problem inspired researchers to organize these strategies, resulting in different attempts to merge the process model of emotion regulation (Gross, 1998) - which was originally designed to organize the range of emotion regulation strategies with the study of self-control (e.g., Duckworth et al., 2016; Magen \& Gross, 2014; O’Leary et al., 2017). While organizing strategies is essential, so far existing models remain silent on key aspects of the self-control process. Namely, what initiates the need for selfcontrol in the first place? And how do people actually use these different strategies? To answer these questions, we propose an extended process model of self-control.

This extended process model of self-control draws inspiration from the process model of emotion regulation (Gross, 2015). Emotion regulation refers to the attempts to influence the types of emotions people experience, when they experience them, and how they are expressed (Gross, 1998). In our view, this is a natural starting point because self-control is an inherently affective process focused on regulating desires that conflict with important personal goals (Hofmann \& Van Dillen, 2012; Hofmann et al., 2012; Kotabe \& Hofmann, 2015). Because of its affective nature, we propose that self-control is far more similar to emotion regulation than their independent literatures would suggest. The most notable similarity is that both self-control and emotion regulation focus on regulatory processes that promote goal attainment (Inzlicht et al., 2021; Tamir, 2021). The key difference, however, is that the ultimate goal of self-control is most often to regulate a person's behaviour (e.g., to stop oneself from eating a delicious but unhealthy snack) whereas the ultimate goal of emotion regulation is to regulate a person's emotions (e.g., to increase positive emotions when having a bad day). But the conceptual overlap between self-control and emotion regulation is already apparent when one considers that people also regulate emotional behaviours through emotion regulation (e.g., to put a smile on one's face), and that people often target emotion processes when engaging in self-control (e.g., reducing the emotional desire posed by that delicious snack). Indeed, while most instances of self-control can be considered emotion regulation (e.g., regulating one's behaviour to reduce desire), not all instances of emotion regulation can be considered self-control (e.g., increasing positive emotions because a person doesn't want to feel bad).

The unique contributions of the extended process model of self-control are twofold. First, we build upon previous process models of self-control by providing a more complete account of how self-control unfolds in everyday life, focusing specifically on how people experience self-control in-the-moment. Second, by bridging the self-control and emotion regulation divide, we bring together concepts and methods pioneered in the emotion regulation literature to better understand how people can achieve their goals. Such integration not only facilitates the use of common language across sub-disciplines (a practice that is sorely needed within self-regulation and psychology more broadly; Werner et al., 2022), but would also be of great practical utility to researchers, practitioners, and people who are generally interested in regulatory processes. 


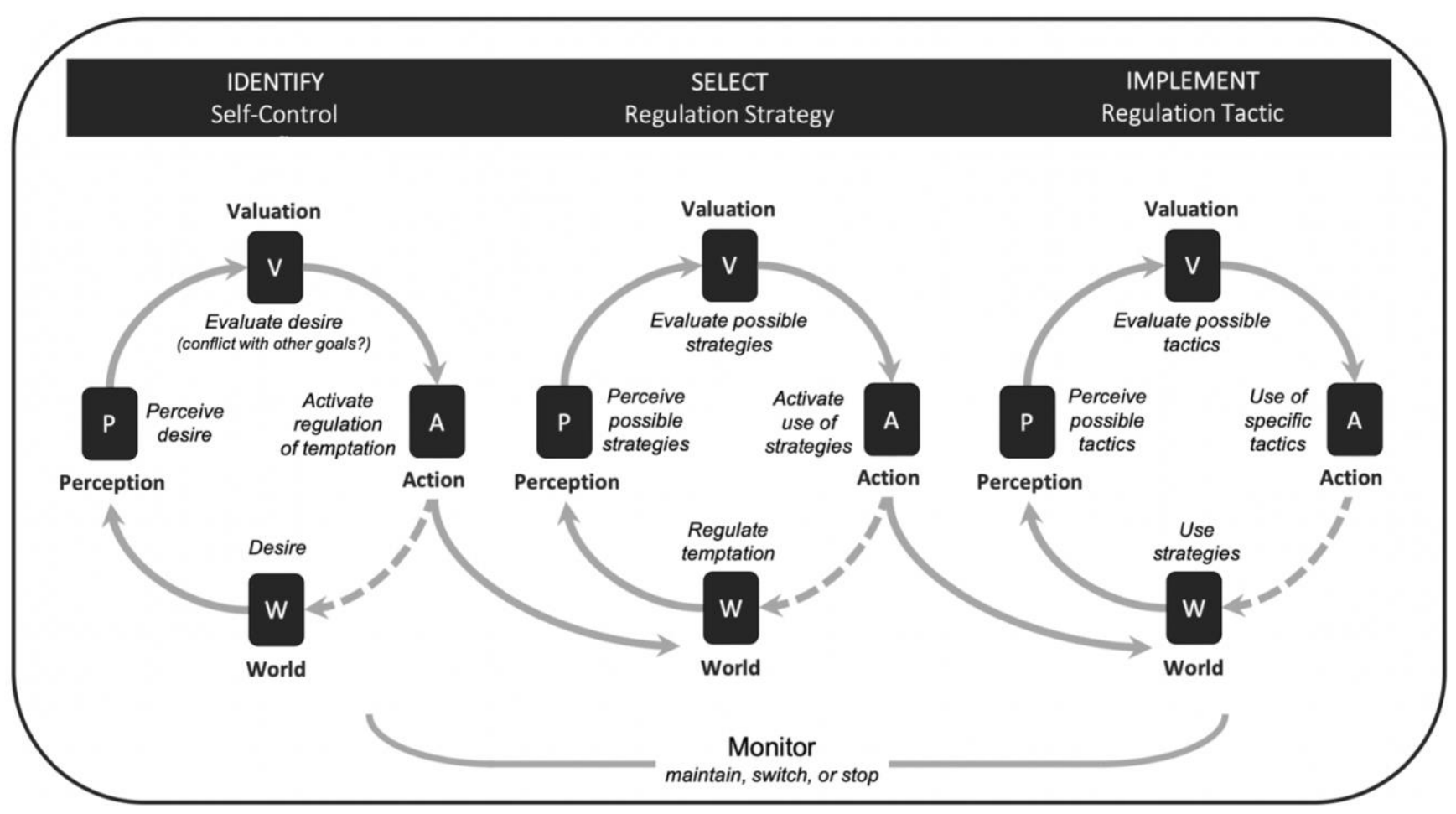

Figure 1. The extended process model of self-control inspired by and adapted from Gross (2015).

Notes. This theoretical model depicts the most common pathway for describing the self-control process (i.e., regulating a temptation). Here, we describe the specific pathway for regulating a temptation (e.g., to avoid unhealthy snacking). However, this same process can be applied to the regulation of the longer-term goal (e.g., to eat healthy) or the simultaneous regulation of both the temptation and the longer-term goal.

\section{An Overview of the Extended Process Model}

In the extended process model of self-control, we propose that self-control is a dynamic, multi-stage process (see Figure 1). People first identify the need to regulate a long-term goal (e.g., to eat healthy) or temptation (e.g., wanting a delicious cookie). They then select what strategies they will use and subsequently implement those strategies by transforming them into corresponding tactics (i.e., specific thoughts, behaviours, or actions). Throughout this process, people monitor progress at each stage, deciding when to maintain, switch, or abandon the current process. At each stage, we consider self-control as a cycle whereby the current state of the world (W), like a goal, is perceived $(\mathrm{P})$ and evaluated $(\mathrm{V})$, resulting in an action (A) that may be launched to change the state of the world (e.g., achieving the goal; cf. Gross, 2015; Rangel et al., 2008). Here, we adapt the process model of emotion regulation which provides the necessary structural foundation, and then we further integrate relevant theories of self-regulation that help generate new predictions, therefore enhancing our understanding of how people regulate temptations and desires in their everyday life. Table 1 provides an overview of key terms that we use to describe the different components and processes outlined in this framework.

\section{Identification: Choosing Which Regulation Goals to Pursue}

Overview of the Identification Stage. The first stage involves identifying the need for self-control. As demonstrated in Figure 1, the identification stage involves experiencing a desire, which represents the current state of the world (W). The desire is first detected at the perception step (P), and then its subjective value is evaluated based on its perceived benefits and costs at the valuation step $(\mathrm{V})$. Because the core feature of self-control is the ability to regulate conflict (either consciously or unconsciously) between 
Table 1. List of key terms.

\begin{tabular}{ccc}
\hline Construct & Definition & Key Citations \\
\hline Components of Self-Control & & \\
\hline
\end{tabular}

Self-control

Desire

Temptation

Goal

Conflict

\section{Regulating Temptations and Desires}

Strategy

Tactic

Repertoire

(or regulatory toolbox)

Polyregulation

Regulatory flexibility
The process of resolving conflict between two (or more) competing goals, that are often (but not always) short-term versus long-term in nature

An affectively charged motivation toward a certain object, person, or activity

A desire that conflicts with a personally important goal or behaviours (i.e., a "problematic" desire)

A cognitive representation of a desired end state that a person is committed to attain

Discrepancy between goals, desires, thoughts, emotions, and/or behaviours that are simultaneously active, mutually exclusive, and compete for a single response
Inzlicht, Werner, Briskin, and Roberts (2021)

Duckworth, Gendler, and Gross (2016)

Hofmann and van Dillen (2012)

Hofmann and Kotabe (2014)

Hofmann, Förster, Vohs, and Baumeister (2012)

Hofmann, Vohs, and Baumeister (2012)

Milyavskaya and Werner (2018)

Elliot and Fryer (2008)

Inzlicht, Werner, Briskin, and Roberts (2021)

Hofmann and van Dillen (2012)
A mean to actively alter one's cognitive, motivational, affective, or behavioral reactions to a self-regulatory challenge in order to achieve a goal

Specific regulatory actions that are used to implement a chosen strategy

The strategies (or tactics) a person generally has at their disposal in the pursuit of particular goal - the tools a person has in their regulatory toolbox

Using more than one approach to regulate a particular instance of a temptation, desire, or goal. Polyregulation can occur at all stages of regulation, including the pursuit of multiple goals, multiple strategies, and/or multiple tactics.

The variation in the use of one or more regulatory strategies (or tactics) across a number of situations - a necessary but not sufficient condition for flexibility

The ability to implement regulatory strategies and/or tactics in accordance with contextual demands
Hennecke, Czikmantori, and Brandstatter (2019)

Duckworth, Milkman, and Laibson (2018)

McRae, Ciesielwski, and Gross (2012)

Ford, Gross, and Gruber (2019)

Bonanno and Burton (2013)

Kalokerinos and Koval (2022)

Ford, Gross, and Gruber (2019)

Werner and Gross (in-preparation)

Aldao, Sheppes, and Gross (2015)

Blanke et al. (2020)

Aldao, Sheppes, and Gross (2015)

Bonanno and Burton (2013) 
two competing goals (e.g., wanting to stay in bed vs. needing to exercise), we propose these goals are simultaneously co-evaluated at this valuation step: the subjective value of the desire is weighed against the subjective value of the long-term goal. When sufficient conflict is detected, the desire becomes a temptation and the need for self-control is triggered at the action step (A). If a desire does not conflict with any other long-term goals, then the desire is perceived, evaluated, and if determined to be sufficiently positively valued, it will be actively pursued (e.g., hitting the snooze button for an extra 30-minutes).

Theoretical Integration. To understand the underpinnings of this first stage, we integrate the model of value-based choice (Berkman, 2018; Berkman, Hutcherson, et al., 2017), which provides an important foundation for how people make goal-related decisions. Desires are not inherently problematic (Hofmann et al., 2012; Hofmann et al., 2014), and so the first step is to identify conflict (Hofmann et al., 2012; Myrseth \& Fishbach, 2009). Drawing from work in economics, psychology, and computational neuroscience, the model of value-based choice proposes that options are evaluated through a neurologically-based value accumulation process where (1) subjective value is the weighted sum of choice-relevant attributes (which can vary across people, context, time), and (2) neurons track subjective value in a noisy but probabilistic fashion until a desired threshold of enactment is reached. Value is accumulated across time, where the option with the greatest subjective value is ultimately enacted (Lin et al., 2018). For example, if a person really enjoys exercise and it is an integral part of their identity (Berkman et al., 2017; O’Leary et al., 2017), they will be less tempted to stay in bed on a cold morning - in fact, such a desire may not even cross their mind in the first place. However, as is often the case with self-control, an internal struggle occurs when two or more options have reached the desired threshold and are of similar value (e.g., having the desire to stay in bed when they know they should exercise as planned). Thus, the closer in value the different choice options, the more conflict is experienced, therefore activating the need for self-control (which can involve decreasing the value of the temptation, increasing the value of the long-term goal, or both).

\footnotetext{
${ }^{1}$ Although research typically defines response modulation as largely involving the use of 'willpower' (e.g., Katzir et al., 2021; Milyavskaya et al., 2021), we do not agree with this approach. As we propose elsewhere (Werner et al., 2022), willpower is not a strategy that can be 'used' and
}

\section{Selection: Choosing Which Regulatory Strategies to Use}

Overview of the Selection Stage. Once a person identifies the need for self-control, they then choose what strategies to use to help prevent and/or resolve conflict. As demonstrated in Figure 1, potential strategies are detected at the perception step (P) and then evaluated based on their perceived benefits and costs within a given context (e.g., based on domain, the person's motivation) at the valuation step (V). If a strategy is sufficiently positively valued, it is selected at the action step (A). For example, when trying to downregulate the temptation to stay in bed on a cold morning, a person would need to perceive what strategies are available to them (e.g., is there a way to change the environment or their thoughts to minimize the temptation?). They would then evaluate which strategies would be most effective for the situation, and the ones that are determined to be sufficiently positively valued would be chosen.

Theoretical Integration. To understand the types of strategies that people can choose at the selection stage, we integrate the process model of self-control (Duckworth et al., 2016; Magen \& Gross, 2014). Researchers have long been studying a myriad of strategies people use to rein in errant impulses - some strategies focus on changing the situation (Duckworth et al., 2016; Hofmann \& Kotabe, 2012) while others focus on changing one's own internal perceptions (Fujita et al., 2006; Mischel et al., 1989); some strategies are consciously enacted (Duckworth, White, et al., 2016; Giuiliani et al., 2013) while others are more implicit (Fishbach \& Shah, 2006; Papies et al., 2008); strategies may be employed by the self (Milkman et al., 2014; Oettingen \& Gollwitzer, 2013) or by others (Benartzi \& Thaler, 2013; Goldstein et al., 2008). The primary aim of the process model of self-control was to taxonomize this never-ending range of strategies into four strategy families: Changing or modifying the environment to avoid temptations (situational strategies), directing attention to features of the situation that facilitate self-control (attentional deployment), changing the way they think about the situation (cognitive change), or focusing on directly influencing the experiential, behavioural, or physiological response once the temptation has fully developed (response modulation ${ }^{1}$ ). While such organization is important, we further propose that strategy selection and effectiveness is largely a function

instead is the target outcome of the self-control process (i.e., the aim is to inhibit unwanted temptations). Instead, we suggest that researchers focus on tractable strategies associated with response modulation (e.g., behavioural modification, expressive suppression; Gross, 1998, 2015). 
of (1) a person's strategy repertoire (i.e., the strategies a person generally has at their disposal), and (2) contextual features that stem from the person, situation, or broader culture (Aldao et al., 2015; Bonnano \& Burton, 2013). In other words, there is no "one strategy to rule them all" - as was originally suggested instead, strategies can be used flexibly depending on context, either on their own or in a series of blends or sequences.

\section{Implementation: Transforming Strategies into Specific Tactics}

Overview of the Implementation Stage. The task of the implementation stage is to translate strategies into tactics that best match the situation. Strategies and tactics are best thought of as a continuum, such that strategy "families" are broad categories and tactics are the more specific ways that a strategy can be operationalized at a given moment in time (Ford et al., 2019; McRae et al., 2012). As demonstrated in Figure 1 , potential tactics are detected in the perception step (P) and are then evaluated based on their subjective benefits and costs within a given context at the valuation step (V). If a tactic is sufficiently positively valued, the tactic is implemented at the action step (A). For example, if a person chooses cognitive change, they then perceive what tactics are available to them (e.g., thinking about how good they will feel after their workout vs. thinking about the negative consequences of sleeping in) and evaluate which option would be most effective. Chosen tactics are then implemented, resulting in the final behavioural output - if successful, the person gets out of bed; if unsuccessful, they roll over and go back to sleep.

Theoretical Integration. To further understand tactics, we integrate research on approach and avoidance motivation (Davidson, 1998; Elliot \& Fryer, 2008; Elliot \& Thrash, 2001). While comparing the effectiveness of self-control strategies has generated important insights for self-control, this focus has deemphasized the variability that exists within any given strategy family. To address this gap, we propose that tactics can be conceptualized as goal-oriented (i.e., behaviours focused on approaching a long-term goal) or temptation-oriented (i.e., behaviours focused on avoiding temptations) (see also Fishbach \& Converse, 2010; Stok et al., 2016). Examples of how people may operationalize different strategies are presented in Table 2. This distinction is critical because avoidancebased tactics can help a person move away from undesired outcomes, however, they do not provide the means to actively move toward the desired goal. For example, getting out of bed is not sufficient to help a person exercise. To achieve this goal, a person still needs to use approach-based tactics to actively head to the gym. In other words, while avoidance-based tactics can help a person "survive" a self-control dilemma, approach-based tactics are necessary to "thrive" in the pursuit of long-term goals.

\section{Monitoring: Knowing When to Maintain, Switch, or Stop a Chosen Approach}

Overview of Monitoring Processes. At each stage, monitoring processes determine if the regulatory goals, strategies, or tactics should be maintained, switched, or stopped. Certain strategies or tactics are stopped when the goal is attained. Strategies or tactics are maintained when the goal has not yet been attained, but the strategies or tactics are still a suitable match for the situation. In cases where the chosen strategies or tactics do not help the person make sufficient progress, there are two potential outcomes: switch the regulatory approach or give in to the temptation. If the goal to regulate the temptation is still active (and the person has not yet given in), the process can loop back to the selection stage (choosing a different strategy) or implementation stage (choosing a different tactic without changing strategies) to try again. This process can repeat until an effective approach is used, resulting in the enactment of the target behaviour (exercising) or giving in to the temptation (staying in bed). In the latter case, the regulatory event is over, and the broader goal system gets updated based on the failure feedback (i.e., there is now a greater discrepancy between one's current and desired end states).

Theoretical integration. To further understand the underpinnings of such monitoring processes, we integrate the cybernetic model (Carver \& Scheier, 1982, 2012), which provides an important conceptual foundation for incorporating feedback into one's goal system. Central to the cybernetic model is a comparator function that monitors the current state of the world (e.g., post-regulation) and compares it to the goal to determine how much progress has been made (e.g., was the temptation successfully resisted?). When a person has not made sufficient progress on their goal, action is taken to reduce this discrepancy. Although the comparator function is most salient after implementing a tactic, this comparator function can be triggered at any stage of the process. This is important because knowing how and when to adjust a regulatory process at each stage is essential for successful self-control (Carver \& Scheier, 2012; Gross, 2015; Inzlicht et al., 2021; Tamir, 2020; Wilkowski \& Ferguson, 2016). 


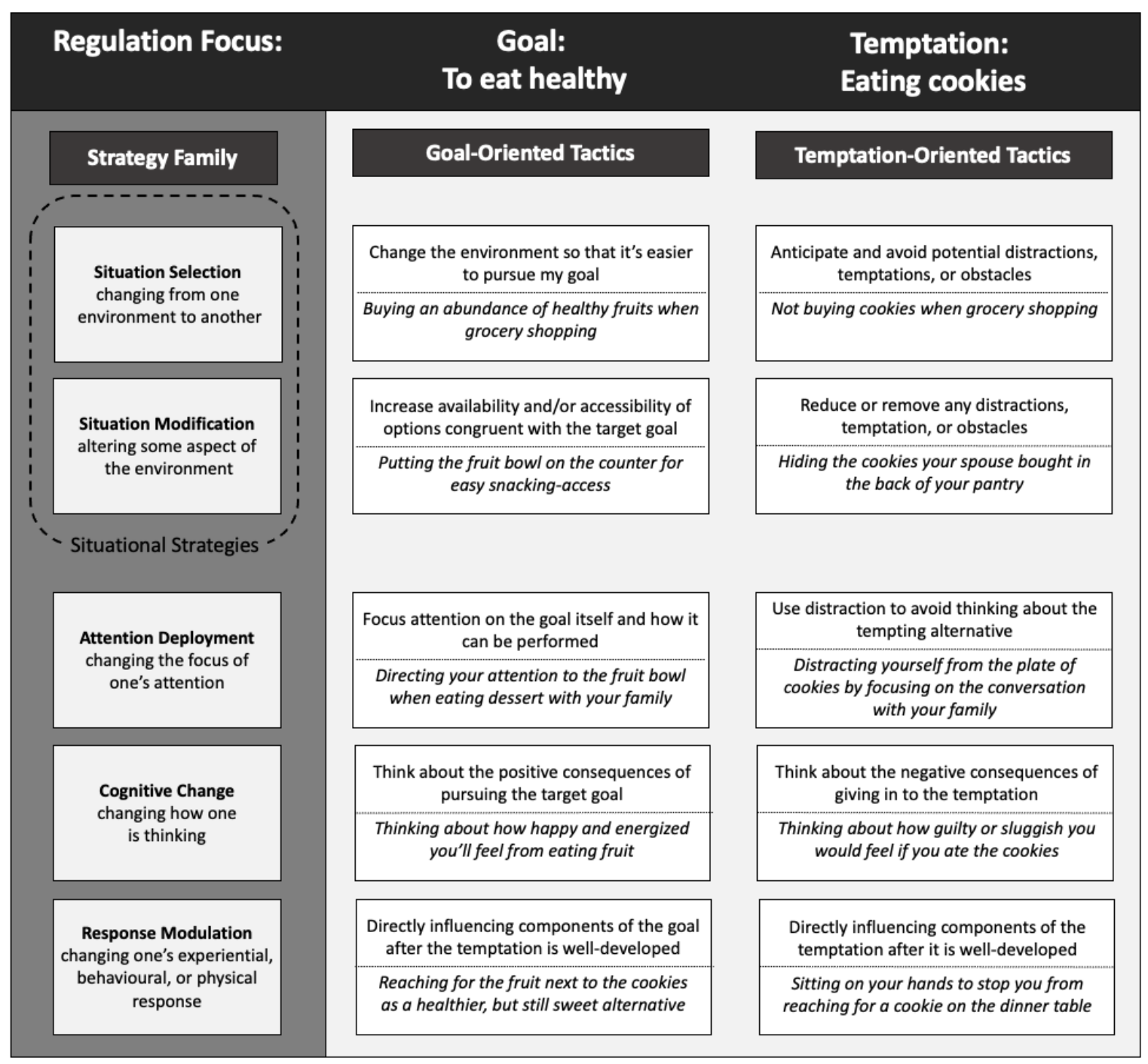

Figure 2. Self-control strategies and example tactics (adapted from Ford et al., 2019).

Notes. In the present framework, we combine situation selection and situation modification into one broader "situational strategies" family. However, to be consistent with previous models (e.g., Duckworth et al., 2016), we define them separately in this table.

\section{Interim Summary}

The extended process model of self-control describes self-control as a dynamic, multi-stage process that unfolds over time. While the previous version of the process model focused exclusively on organizing different strategy types (Duckworth et al., 2016), the extended process model provides a parsimonious description of how self-control unfolds in everyday life from start (when the need for self-control is activated) to finish (giving into temptation or not). Such expansion is crucial, as research on self-control thus far has predominantly focused on why people fail (as was the case in the ego depletion era; e.g., Baumeister et al., 2007) or contrasting specific strategies to determine their effectiveness (as is the case in the current "beyond willpower" era; e.g., Milyavskaya et al., 2021). While important, these perspectives have not yet fully considered processes before (i.e., identifying the need for self-control) and after (i.e., translating strategies into actionable tactics), which we emphasize in the extended process model of self-control. Additionally, by integrating different theories and perspectives to describe the self-control process more fully, this framework helps move the field toward a more unified science of self-control while also setting the stage for a new generation of research. 


\section{Growth Points to Guide Future Research on Self-Control}

In addition to its theoretical contributions, the extended process model of self-control is intended to facilitate the next generation of research on selfcontrol. Here, we outline four exciting growth points for the field. In some ways, these growth points can be viewed as a translation of key constructs from emotion regulation as they apply to the study of self-control. However, even within emotion regulation there is an overwhelming amount of conceptual ambiguity among key constructs (Gross, 2015), especially at the empirical level (Werner et al., 2022). We address these concerns by disentangling different components of the regulatory process (i.e., strategy repertoire, flexibility, polyregulation) and describe each of them as they apply to research on self-control.

\section{Considering a Toolbox Approach to Self-Control}

The selection stage highlights how people can use a wide range of self-control strategies. However, a person's capacity to regulate depends on their strategy repertoire, or the strategies a person generally has at their disposal in the pursuit of a particular goal (Bonanno \& Burton, 2013). This concept is best described as a "toolbox" approach to self-control much like a carpenter needs to have different tools to carry out their work successfully, strategy repertoire represents a person's regulatory "toolbox" and the individual strategies represent the "tools" they use to pursue their goals. To date, self-control research has predominantly focused on contrasting specific strategies to determine their effectiveness (e.g., De Vet et al., 2014; Hennecke et al., 2019; Milyavskaya et al., 2021) and has yet to fully consider individual differences in the range of strategies people can use to overcome temptation in the pursuit of their goals.

While strategy repertoire has been a topic of interest in emotion regulation for the last decade, it is only just emerging in research on self-control. The consensus so far seems to be that having a larger strategy repertoire is beneficial (e.g., Lam \& McBride-Chang, 2007; Lougheed \& Hollenstein, 2012). However, findings from recent self-control studies suggest that having a larger strategy repertoire can be beneficial in some cases, but not all (Bürgler et al., 2021; Werner et al., 2022), which is consistent with emerging work on emotion regulation (Southward et al., 2018). Although most research focuses on repertoire size, it is also important to consider composition. In fact, research suggests that the composition of a person's strategy repertoire likely carries more weight than size alone (Grommisch et al., 2020; see Kalokerinos \& Koval, 2020).

As the field expands beyond the study of individual strategies, researchers can explore a series of generative questions that allow us to better understand the complexities of self-control in everyday life. First, is there an ideal strategy repertoire? To answer this question, research can expand beyond the size of a person's repertoire to include the types of strategies people have in their toolbox, and the degree to which those strategies are used. Second, who is more likely to have a well-equipped strategy repertoire? By exploring developmental, socio-cultural, and personality factors that influence repertoire development, we can learn a lot from the people who naturally develop a wellequipped strategy repertoire, while also identifying important points for intervention. Finally, is strategy repertoire general or goal-specific? Self-control is domain-specific (Tsukayama et al., 2012), suggesting that people may use strategies differently for different goals (e.g., health vs. financial goals). Thus, if we want to actually help people achieve their goals, research also needs to consider how regulatory processes can be tailored for the different goals people pursue.

\section{Self-Control is Flexible}

While having a well-equipped strategy repertoire is necessary for self-control, it alone is not sufficient for success. Having access to an array of strategies allows for the possibility to accommodate a wider range of situations; however, just because a person has the right "tools" does not necessarily mean they know how and when to use them. Building on this toolbox approach, we propose that it is important to know when and how to use strategies and their corresponding tactics based on context (Aldao et al., 2015; Bonanno \& Burton, 2013). The ability to dynamically choose strategies and/or tactics that best match the context, or regulatory flexibility, can enhance regulatory success (Aldao et al., 2015; Southward \& Cheavens, 2020a, 2020b). Critically, regulatory flexibility is distinct from regulatory variability, or the general variation in the use of one or more regulatory strategies (or tactics) across a number of situations (Aldao et al., 2015; English \& Eldesouky, 2020a). For example, frequently and haphazardly using all strategies (i.e., indicating high variability) in the hopes that something works has the potential to backfire (Dixon-Gordon et al., 2015). Instead, we propose that context matters - regulatory flexibility has potential to enhance self-control success, so long as a person has a well-equipped strategy 
repertoire and the ability to evaluate strategies and tactics in a way that best match the situation.

Although essential for regulatory flexibility, research so far has been rather silent on the role of context. This is likely because measuring regulatory flexibility is incredibly difficult (Kalokerinos \& Kuppens, 2022). Further compounding this issue are individual differences in how researchers operationalize regulatory flexibility, especially at the empirical level. So far, research suggests that people tend to choose strategies based on situational factors (Sheppes et al., 2014). For example, people choose reappraisal in low-intensity situations but disengagement in high-intensity situations (Sheppes et al., 2011). People may also choose strategies depending on specific goals (Greenaway et al., 2021), a finding with preliminary evidence in self-control (Werner \& Gross, in-preparation). Second, the success of a strategy also depends on the situation. Research consistently finds that individual strategies can be effective in certain situations, but can backfire in others (see Ford \& Troy, 2019 for an overview). For example, reappraisal was associated with lower levels of depression for people with uncontrollable stress, but higher levels of depression for people with controllable stress (Troy et al., 2013). Finally, the ability to switch strategies can be beneficial, especially when an initial strategy attempt has failed. Research suggests that switching strategies (i.e., from reappraisal to distraction) predicted greater well-being when this switch was based on internal feedback, but predicted lower well-being when the switch was made haphazardly (Birk \& Bonanno, 2016).

An important first step to studying regulatory flexibility is to start identifying contextual factors that determine when people choose particular goals, strategies, or tactics. Such contextual factors can stem from the person, situation, or broader culture (Greenaway et al., 2018). Here, we identify what we believe are some key contextual factors that can influence self-control strategy use. At the situational level, one of the most relevant factors is conflict intensity. For example, people may choose situational strategies when conflict intensity is high, especially when they can avoid temptation entirely. At the person

\footnotetext{
${ }^{2}$ In their original articles, these two studies assessing polyregulation state that they assess polyregulation in the context of self-control. However, these studies focus specifically on desires and do not take into consideration whether these desires conflict with important personal goals. As discussed in the current framework alongside other self-control research (e.g., Hofmann et al., 2012; Inzlicht et al., 2021), desires are not inherently problematic and thus conflict is essential for studying self-control. It is likely that studying desires more generally (which includes occasions both where people are using self-control and others where they are not) provides a
}

level, external factors like socioeconomic status (Troy et al., 2013) and internal factors like motivation (e.g., de Vet et al., 2011) can influence peoples' preferences for choosing different strategies, as well as their subsequent effectiveness. To test these ideas, researchers can use experiments to address the causal impact of different contextual factors on strategy selection and success (e.g., Sheppes et al., 2014) and/or intensive longitudinal designs (e.g., experience sampling) to better capture the dynamic nature of strategy use in daily life.

\section{Polyregulation Occurs at All Stages of Regulation}

Most research on self-control has examined different regulatory processes in isolation, often focusing on a single goal or strategy. We propose that people likely use multiple approaches within the same regulatory event (e.g., pursuing multiple goals, using multiple strategies, implementing multiple tactics), a concept known as polyregulation (Ford et al., 2019). Indeed, regulating a desire is rarely as simple as choosing a single approach, using it, and then disengaging from it - rather, people can regulate using blends (concurrent polyregulation) and/or sequences (sequential polyregulation) of goals, strategies, or tactics.

Although polyregulation has only recently come into the spotlight, the few studies that directly examine polyregulation have focused on strategies. For example, recent studies examining how people regulate desires $^{2}$ in everyday life find that, although people only use polyregulation on $25 \%$ of occasions, people were more likely to resist desires on occasions where they used polyregulation (Lopez et al., 2021; Milyavskaya et al., 2021). While these studies provide an initial glimpse into strategy polyregulation in the context of self-regulation more broadly, these findings only scratch the surface.

While initial studies provide a glimpse into strategy polyregulation, several key questions remain open for investigation. The most central question being - how common is polyregulation in the context of selfcontrol? Initial studies examined the prevalence of polyregulation when regulating desires, however,

biased (low) estimate of how common polyregulation is, as there is less of a need to use strategies, let alone multiple strategies, when there is no conflict to regulate in the first place. It is important not to conflate self-control (which requires conflict) and self-regulation more broadly (which does not require conflict), as this conflation has contributed to a long-standing lack of conceptual clarity surrounding the distinctions between these important constructs (see Inzlicht et al., 2021 and Milyavskaya et al., 2019 for further conceptual clarification). 
future research would benefit from examining how common polyregulation is when faced with actual selfcontrol conflicts. Relatedly, a second key question is when do people use polyregulation? Depending on the context, people may choose to (or may be required to) use multiple regulatory approaches at the same time, such as when conflict intensity is high (Dorman Ilan et al., 2019; Kalokerinos et al., 2017; Parsafar et al., 2019). A more obvious case where polyregulation may be helpful is when an initial strategy attempt fails - in this case, a person can change strategies (strategy polyregulation) or change tactics (tactic polyregulation). A third key question is - who uses polyregulation? The likely answer is that almost everyone uses polyregulation to some degree, so it would be helpful to know how individual differences (e.g., socioeconomic status, repertoire size) influence polyregulation. Finally, a fourth key question - is polyregulation effective? Polyregulation is neither inherently adaptive nor maladaptive - people can engage in a goal, strategy, and/or tactic combinations that work in concert, cancel each other out, or even backfire. Thus, future research would benefit from identifying the effectiveness of specific combinations of goals, strategies, or tactics across contexts.

\section{Self-Control Interventions}

With the rapidly growing interest in understanding how self-control unfolds in everyday life alongside recent theoretical advancements, there is a compelling need to formulate and test interventions that can leverage existing insights and inform real-world behaviour change. While self-control interventions can take on many forms (e.g., Knittle et al., 2020), here we focus on two particularly promising avenues moving forward: (1) teaching people how to use strategies more effectively and (2) shifting a person's motivation to promote lasting behaviour change.

The process model of self-control (Duckworth et al., 2016) has been particularly revolutionary in proposing that using strategies to change one's environment is the key to success - that is, removing temptations from your environment can be more successful compared to strategies people use to cope with temptations that are already present (e.g., cognitive change, attention deployment). While there have been several recent experience sampling studies providing mixed results for this "earlier is better" hypothesis (Hennecke et al., 2019; Lopez et al., 2021; Milyavskaya et al., 2021; Williamson \& Wilkowski, 2020), two intervention studies found that situational strategies predict better goal progress (Duckworth, White et al., 2014). Given that we are still at the beginning of this major theoretical shift in research on self-control, future research would benefit from designing interventions to test foundational ideas such as (1) whether and to what degree situational strategies lead to experiencing fewer temptations in everyday life, (2) examining the causal effectiveness of the range of self-control strategies across different domains (especially compared to other strategies that are not willpower; see Werner et al., 2022), (3) examining the extent to which different contextual factors (e.g., socioeconomic status, motivation) influence the effectiveness of individual strategies in-the-moment (e.g., are there certain contexts where situational strategies are effective, but others where they backfire?), and (4) whether people can be taught to flexibly use strategies on their own or in specific combinations (e.g., choosing a "back-up" strategy after a first attempt failed).

Strategy interventions are useful in helping people prevent and/or manage temptations, but what if people didn't need self-control in the first place? While such a proposal is quite lofty, there is evidence to suggest that getting people to genuinely want to pursue their goals can help bypass the need for self-control and instead facilitate the development of better habits (e.g., Berkman, Livingston, et al., 2017; Fishbach \& Woolley, 2021; Leduc-Cummings et al., 2022; Milkman et al., 2008; Milyavskaya et al., 2015; Rozin, 1990; Werner \& Milyavskaya, 2018). Indeed, a growing body of research suggests that pursuing wantto goals (e.g., goals that are genuinely enjoyable, personally important, and/or and relevant to a person's identity) is associated with greater preference for goalcongruent options (e.g., healthy foods like fruits and vegetables) and less of a preference for more "tempting" goal-incongruent options (e.g., unhealthy snacks) (Dominick \& Cole, 2020; Leduc-Cummings et al., 2022; Milyavskaya et al., 2015). This suggests that want-to goals may not need self-control because there is no need to regulate oneself around "temptations," as they are inherently perceived as less desirable. Thus, developing interventions that (1) encourage people to set more want-to goals, or (2) dynamically shift a person's motivation to being more intrinsic can help people make better goal-related decisions that can ultimately promote lasting behaviour change (Berkman, 2018; Gardner \& Lally, 2018).

\section{Concluding Comment}

Research on self-control has reached the point where the field can now more fully consider the complexities of self-control processes as they occur in 
everyday life. To further support the theoretical and practical recommendations we have made, we also believe it is important to carefully consider further integrating across different fields to enhance the science and practice of self-control.

Self-control is a widely applicable process that plays a key role in nearly all subfields in psychology (e.g., health, education, developmental) and adjacent fields (e.g., neuroscience, economics). However, despite these overlapping interests, researchers often work in their respective siloes which limits valuable crosstalk for people studying the same topics and has led to a largely fragmented field. This fragmentation is understandable - when different subfields publish their findings in different journals and use different terms to refer to the same construct (i.e., jangle fallacy; Kelley, 1927), it can be challenging to find points of commonality. However, as we have demonstrated in the present framework, it is crucial that we as a field continue to build a more comprehensive and cumulative science (e.g., Lin et al., 2020). While we were able to provide a roadmap to guide future research, by no means is this a complete endeavour and so we strongly encourage researchers to continue building empirical bridges across different perspectives, domains, and fields. By working together, we can collectively develop a more cumulative science on the study of self-control that includes strong theories and methods.

\section{References}

Adriaanse, M. A., Vinkers, C. D. W., De Ridder, D. T. D., Hox, J. J., \& De Wit, J. B. F. (2011). Do implementation intentions help to eat a healthy diet? A systematic review and meta-analysis of the empirical evidence. Appetite, 56(1), 183-193.

Aldao, A., Sheppes, G., \& Gross, J. J. (2015). Emotion Regulation Flexibility. Cognitive Therapy and Research, 39(3), 263-278.

Baranski, E., Gray, J., Morse, P., \& Dunlop, W. (2020). From desire to development? A multi-sample, idiographic examination of volitional personality change. Journal of Research in Personality, 85, 103910.

Baumeister, R. F. (2002). Ego depletion and self-control failure: An energy model of the self's executive function. Self and Identity, 1, 129-136.

Baumeister, R. F., Vohs, K. D., \& Tice, D. M. (2007). The strength model of self-control. Current Directions in Psychological Science, 16, 351355.

Becker, D., Jostmann, N. B., Hofmann, W., \& Holland, R. W. (2019). Spoiling the pleasure of success: Emotional reactions to the experience of self-control conflict in the eating domain. Emotion, 19, 1377-1395.

Berkman, E. T. (2018). Value-based choice: An integrative, neuroscienceinformed model of health goals. Psychology \& Health, 33, 40-57.

BeAldao, A., Sheppes, G., \& Gross, J. J. (2015). Emotion Regulation Flexibility. Cognitive Therapy and Research, 39(3), 263-278. https://doi.org/10.1007/s10608-014-9662-4

Baumeister, R. F. (2002). Ego depletion and self-control failure: An energy model of the self's executive function. Self and Identity, 1, 129-136.

Baumeister, R. F., Vohs, K. D., \& Tice, D. M. (2007). The strength model of self-control. Current Directions in Psychological Science, 16, 351355.
Benartzi, S., \& Thaler, R. H. (2013). Behavioral Economics and the Retirement Savings Crisis. Science, 339, 1152-1153. https://doi.org/10.1126/science.1231320

Berkman, E. T. (2018). Value-based choice: An integrative, neuroscienceinformed model of health goals. Psychology \& Health, 33, 40-57. https://doi.org/10.1080/08870446.2017.1316847

Berkman, E. T., Hutcherson, C. A., Livingston, J. L., Kahn, L. E., \& Inzlicht, M. (2017). Self-control as value-based choice. Current Directions in Psychological Science, 26, 422-428. https://doi.org/10.1177/0963721417704394

Birk, J. L., \& Bonanno, G. A. (2016). When to throw the switch: The adaptiveness of modifying emotion regulation strategies based on affective and physiological feedback. Emotion, 16, 657-670. https://doi.org/10.1037/emo0000157

Bonanno, G. A., \& Burton, C. L. (2013). Regulatory flexibility: An individual differences perspective on coping and emotion regulation. Perspectives on Psychological Science, 8, 591-612. https://doi.org/10.1177/1745691613504116

Bürgler, S., Hoyle, R. H., \& Hennecke, M. (2021). Flexibility in Using SelfRegulatory Strategies to Manage Self Control Conflicts: The Role of Metacognitive Knowledge, Strategy Repertoire, and Feedback Monitoring. European Journal of Personality.

Carver, C. S., \& Scheier, M. F. (1982). Control theory: A useful conceptual framework for personality-social, clinical, and health psychology. Psychological Bulletin, 92, 111-135. https://doi.org/10.1037/00332909.92.1.111

Carver, C. S., \& Scheier, M. F. (2012). A Model of Behavioral SelfRegulation. In A. Kruglanski \& E. Higgins (Eds.), Handbook of Theories of Social Psychology: Volume 1 (pp. 505-525). SAGE Publications Ltd. https://doi.org/10.4135/9781446249215.n25

Davidson, R. J. (1998). Anterior electrophysiological asymmetries, emotion, and depression: Conceptual and methodological conundrums. Psychophysiology, 35, https://doi.org/10.1017/S0048577298000134

de Vet, E., de Ridder, D., Stok, M., Brunso, K., Baban, A., \& Gaspar, T. (2014). Assessing self-regulation strategies: Development and validation of the tempest self-regulation questionnaire for eating (TESQ-E) in adolescents. International Journal of Behavioral Nutrition and Physical Activity, 11. https://doi.org/10.1186/s12966-014-0106-z

Dixon-Gordon, K. L., Aldao, A., \& De Los Reyes, A. (2015). Emotion regulation in context: Examining the spontaneous use of strategies across emotional intensity and type of emotion. Personality and Individual Differences, 86, 271-276. https://doi.org/10.1016/j.paid.2015.06.011

Dominick, J. K., \& Cole, S. (2020). Goals as identities: Boosting perceptions of healthy-eater identity for easier goal pursuit. Motivation and Emotion, 44, 410-426. https://doi.org/10.1007/s11031-020-09824-8

Dorman Ilan, S., Shafir, R., Birk, J. L., Bonanno, G. A., \& Sheppes, G. (2019). Monitoring in emotion regulation: Behavioral decisions and neural consequences. Social Cognitive and Affective Neuroscience, 14, 1273-1283. https://doi.org/10.1093/scan/nsaa001

Duckworth, A. L., Gendler, T. S., \& Gross, J. J. (2016). Situational strategies for self-control. Perspectives on Psychological Science, 11, 35-55. https://doi.org/10.1177/1745691615623247

Duckworth, A. L., Milkman, K. L., \& Laibson, D. (2018). Beyond willpower: Strategies for reducing failures of self-control. Psychological Science in the Public Interest, 19, 102-129. https://doi.org/10.1177/1529100618821893

Duckworth, A. L., White, R. E., Matteucci, A. J., Shearer, A., \& Gross, J. J. (2016). A stitch in time: Strategic self-control in high school and college students. Journal of Educational Psychology, 108, 329-341. https://doi.org/10.1037/edu0000062

Elliot, A. J., \& Fryer, J. W. (2008). The goal construct in psychology. In J. Y. Shah \& W. L. Gardner (Eds.), Handbook of motivation science (pp. 235-250). Guilford Press.

Elliot, A. J., \& Thrash, T. M. (2001). Approach-avoidance motivation in personality: Approach and avoidance temperaments and goals. Journal of Personality and Social Psychology, 13, 139-156.

English, T., \& Eldesouky, L. (2020). Emotion Regulation Flexibility: Challenges and Promise of Using Ecological Momentary Assessment. European Journal of Psychological Assessment, 36, 456-459. https://doi.org/10.1027/1015-5759/a000581 
Federal Reserve Bank of New York. (2020). Quartely report on household debt and credit (2020: Q3; pp. 1-43). Center for Microeconomic Data. https://www.newyorkfed.org/medialibrary/interactives/householdcredit/ data/pdf/HHDC_2020Q3.pdf

Fishbach, A., \& Converse, B. A. (2010). Identifying and battling temptation. In Handbook of self-regulation: Research, theory, and applications (pp. 244-260).

Fishbach, A., \& Shah, J. Y. (2006). Self-control in action: Implicit dispositions toward goals and away from temptations. Journal of Personality and Social Psychology, 90, 820-832. https://doi.org/10.1037/0022-3514.90.5.820

Fishbach, A., \& Woolley, K. (2022). The Structure of Intrinsic Motivation. Annual Review of Organizational Psychology and Organizational Behavior, 9, 339-363. https://doi.org/10.1146/annurev-orgpsych012420-091122

Ford, B. Q., Gross, J. J., \& Gruber, J. (2019). Broadening our field of view: The role of emotion polyregulation. Emotion Review, 11, 197-208. https://doi.org/10.1177/1754073919850314

Fujita, K., Orvell, A., \& Kross, E. (2020). Smarter, Not Harder: A Toolbox Approach to Enhancing Self-Control. Policy Insights from the Behavioral and Brain Sciences, 7, 149-156. https://doi.org/10.1177/2372732220941242

Fujita, K., Trope, Y., Liberman, N., \& Levin-Sagi, M. (2006). Construal levels and self-control. Journal of Personality and Social Psychology, 90, 351-367. https://doi.org/10.1037/0022-3514.90.3.351

Gardner, B., \& Lally, P. (2018). Modelling habit formation and its determinants. In The Psychology of Habit (pp. 207-229). Springer.

Giuliani, N. R., Calcott, R. D., \& Berkman, E. T. (2013). Piece of cake. Cognitive reappraisal of food craving. Appetite, 64, 56-61. https://doi.org/10.1016/j.appet.2012.12.020

Goldstein, N. J., Cialdini, R. B., \& Griskevicius, V. (2008). A Room with a Viewpoint: Using Social Norms to Motivate Environmental Conservation in Hotels. Journal of Consumer Research, 35, 472-482. https://doi.org/10.1086/586910

Greenaway, K. H., \& Kalokerinos, E. K. (2017). Suppress for success? Exploring the contexts in which expressing positive emotion can have social costs. European Review of Social Psychology, 28(1), 134-174. https://doi.org/10.1080/10463283.2017.1331874

Greenaway, K. H., Kalokerinos, E. K., Hinton, S., \& Hawkins, G. E. (2021). Emotion experience and expression goals shape emotion regulation strategy choice. Emotion, 21(7), 1452-1469. https://doi.org/10.1037/emo0001012

Grommisch, G., Koval, P., Hinton, J. D. X., Gleeson, J., Hollenstein, T., Kuppens, P., \& Lischetzke, T. (2020). Modeling individual differences in emotion regulation repertoire in daily life with multilevel latent profile analysis. Emotion, 20, 1462-1474. https://doi.org/10.1037/emo0000669

Gross, J. J. (1998). The emerging field of emotion regulation: An integrative review. Review of General Psychology, 2, 271-299.

Gross, J. J. (2015). Emotion Regulation: Current Status and Future Prospects. Psychological Inquiry, 26(1), 1-26. https://doi.org/10.1080/1047840X.2014.940781

Hennecke, M., Czikmantori, T., \& Brandstätter, V. (2019). Doing despite disliking: Self-regulatory strategies in everyday aversive activities. European Journal of Personality. https://doi.org/10.1002/per.2182

Hofmann, W., Baumeister, R. F., Förster, G., \& Vohs, K. D. (2012). Everyday temptations: An experience sampling study of desire, conflict, and self-control. Journal of Personality and Social Psychology, 102, 1318-1335. https://doi.org/10.1037/a0026545

Hofmann, W., \& Kotabe, H. (2012). A general model of preventive and interventive self-control. Social and Personality Psychology Compass, 6, 707-722. https://doi.org/10.1111/j.1751-9004.2012.00461.x

Hofmann, W., Luhmann, M., Fisher, R. R., Vohs, K. D., \& Baumeister, R. F. (2014). Yes, but are they happy? Effects of trait self-control on affective well-being and life satisfaction. Journal of Personality, 82, 265-277. https://doi.org/10.1111/jopy. 12050

Hofmann, W., \& Van Dillen, L. (2012). Desire: The new hot spot in selfcontrol research. Current Directions in Psychological Science, 21, $317-$ 322. https://doi.org/10.1177/0963721412453587

Inzlicht, M., \& Friese, M. (2021). Willpower is overrated. Behavioral and Brain Sciences, 44. https://doi.org/10.1017/S0140525X20000795

Inzlicht, M., Werner, K. M., Briskin, J. L., \& Roberts, B. W. (2021). Integrating Models of Self-Regulation. Annual Review of Psychology, 72, 319-345. https://doi.org/10.1146/annurev-psych-061020-105721
Katzir, M., Baldwin, M., Werner, K. M., \& Hofmann, W. (2021). Moving beyond Inhibition: Capturing a Broader Scope of the Self-Control Construct with the Self-Control Strategy Scale (SCSS). Journal of Personality Assessment, 103, 762-776. https://doi.org/10.1080/00223891.2021.1883627

Kelley, T. L. (1927). Interpretation of educational measurements. World Book Company.

Knittle, K., Heino, M., Marques, M. M., Stenius, M., Beattie, M., Ehbrecht, F., Hagger, M. S., Hardeman, W., \& Hankonen, N. (2020). The compendium of self-enactable techniques to change and self-manage motivation and behaviour v.1.0. Nature Human Behaviour, 4, 215-223. https://doi.org/10.1038/s41562-019-0798-9

Koestner, R., Powers, T. A., Milyavskaya, M., Carbonneau, N., \& Hope, N. (2015). Goal internalization and persistence as a function of autonomous and directive forms of goal support. Journal of Personality, 83, 179-190. https://doi.org/10.1111/jopy.12093

Kotabe, H. P., \& Hofmann, W. (2015). On integrating the components of self-control. Perspectives on Psychological Science, 10, 618-638. https://doi.org/10.1177/1745691615593382

Lam, C. B., \& McBride-Chang, C. A. (2007). Resilience in Young Adulthood: The Moderating Influences of Gender-related Personality Traits and Coping Flexibility. Sex Roles, 56(3-4), 159-172. https://doi.org/10.1007/s11199-006-9159-z

Leduc-Cummings, I., Werner, K. M., Milyavskaya, M., Dominick, J. K., \& Cole, S. (2022). Experiencing obstacles during goal pursuit: The role of goal motivation and trait self-control. Journal of Research in Personality, 99, 104231. https://doi.org/10.1016/j.jrp.2022.104231

Lin, H., Saunders, B., Hutcherson, C. A., \& Inzlicht, M. (2018). Midfrontal theta and pupil dilation parametrically track subjective conflict (but also surprise) during intertemporal choice. NeuroImage, 172, 838-852. https://doi.org/10.1016/j.neuroimage.2017.10.055

Lin, H., Werner, K. M., \& Inzlicht, M. (2021). Promises and perils of experimentation: The mutual internal validity problem. Perspectives on Psychological Science. https://doi.org/10.31234/osf.io/hwubj

Lopez, R. B., Cosme, D., Werner, K. M., Saunders, B., \& Hofmann, W. (2021). Associations between use of self-regulatory strategies and daily eating patterns: An experience sampling study in college-aged women. Motivation and Emotion, 45(6), 747-758. https://doi.org/10.1007/s11031-021-09903-4

Lougheed, J. P., \& Hollenstein, T. (2012). A Limited Repertoire of Emotion Regulation Strategies is Associated with Internalizing Problems in Adolescence: Adolescent Emotion Regulation Patterns. Social Development, 21(4), 704-721. https://doi.org/10.1111/j.14679507.2012.00663.x

Magen, E., \& Gross, J. J. (2010). The cybernetic process model of selfcontrol: Situation-and person-specific considerations. In R. H. Hoyle (Ed.), Handbook of Personality and Self-Regulation (pp. 353-374). Blackwell.

McRae, K., Ciesielski, B., \& Gross, J. J. (2012). Unpacking cognitive reappraisal: Goals, tactics, and outcomes. Emotion, 12, 250-255. https://doi.org/10.1037/a0026351

Milkman, K. L., Minson, J. A., \& Volpp, K. G. M. (2014). Holding the Hunger Games Hostage at the Gym: An Evaluation of Temptation Bundling. Management Science, 60, 283-299. https://doi.org/10.1287/mnsc.2013.1784

Milkman, K. L., Rogers, T., \& Bazerman, M. H. (2008). Harnessing Our Inner Angels and Demons: What We Have Learned About Want/Should Conflicts and How That Knowledge Can Help Us Reduce Short-Sighted Decision Making. Perspectives on Psychological Science, 3(4), 324 338. https://doi.org/10.1111/j.1745-6924.2008.00083.x

Milyavskaya, M., Berkman, E. T., \& De Ridder, D. T. D. (2019). The many faces of self-control: Tacit assumptions and recommendations to deal with them. Motivation Science, 5, 79-85. https://doi.org/10.1037/mot0000108

Milyavskaya, M., Nadolny, D., \& Koestner, R. (2015). Why do people set more self-concordant goals in need satisfying domains? Testing authenticity as a mediator. Personality and Individual Differences, 77 , 131-136. https://doi.org/10.1016/j.paid.2014.12.028

Milyavskaya, M., Saunders, B., \& Inzlicht, M. (2021). Self-control in daily life: Prevalence and effectiveness of diverse self-control strategies. Journal of Personality, 89, 634-651. https://doi.org/10.1111/jopy.12604

Milyavskaya, M., \& Werner, K. M. (2021). An integrative model of goal pursuit. PsyArXiv, https://doi.org/10.31234/osf.io/qydpv 
Mischel, W., Shoda, Y., \& Peake, P. K. (1988). The nature of adolescent competencies predicted by preschool delay of gratification. Journal of Personality and Social Psychology, 54, 687-696.

Mischel, W., Shoda, Y., \& Rodriguez, M. (1989). Delay of gratification in children. Science, 244, 933-938. https://doi.org/10.1126/science.2658056

Moffitt, T. E., Arseneault, L., Belsky, D., Dickson, N., Hancox, R. J., Harrington, H., Houts, R., Poulton, R., Roberts, B. W., Ross, S., Sears, M. R., Thomson, W. M., \& Caspi, A. (2011). A gradient of childhood self-control predicts health, wealth, and public safety. Proceedings of the National Academy of Sciences, 108, 2693-2698. https://doi.org/10.1073/pnas.1010076108

Myrseth, K. O. R., \& Fishbach, A. (2009). Self-Control: A Function of Knowing When and How to Exercise Restraint. Current Directions in Psychological Science, 18, 247-252. https://doi.org/10.1111/j.14678721.2009.01645.x

National Center for Chronic Disease Prevention and Health Promotion. (2019). Lack of physical activity. Centers for Disease Control and Prevention.

https://www.cdc.gov/chronicdisease/resources/publications/factsheets/p hysical-activity.htm

Oettingen, G., Kappes, H. B., Guttenberg, K. B., \& Gollwitzer, P. M. (2015). Self-regulation of time management: Mental contrasting with implementation intentions: MCII for time management. European Journal of Social Psychology, 45, 218-229. https://doi.org/10.1002/ejsp.2090

O’Leary, D., Uusberg, A., \& Gross, J. J. (2017). Identity and self-control: Linking identity-value and process models of self-control. Psychological Inquiry, 28, 132-138. https://doi.org/10.1080/1047840X.2017.1337404

Papies, E. K., Stroebe, W., \& Aarts, H. (2008). The allure of forbidden food: On the role of attention in self-regulation. Journal of Experimental Social Psychology, 44, 1283-1292. https://doi.org/10.1016/j.jesp.2008.04.008

Parsafar, P., Fontanilla, F. L., \& Davis, E. L. (2019). Emotion regulation strategy flexibility in childhood: When do children switch between different strategies? Journal of Experimental Child Psychology, 183, 118. https://doi.org/10.1016/j.jecp.2019.01.004

Roberts, B. W., Lejuez, C., Krueger, R. F., Richards, J. M., \& Hill, P. L. (2014). What is conscientiousness and how can it be assessed? Developmental Psychology, 50, 1315-1330. https://doi.org/10.1037/a0031109

Sheppes, G., Scheibe, S., Suri, G., \& Gross, J. J. (2011). EmotionRegulation Choice. Psychological Science, 22(11), 1391-1396. https://doi.org/10.1177/0956797611418350

Sheppes, G., Scheibe, S., Suri, G., Radu, P., Blechert, J., \& Gross, J. J. (2014). Emotion regulation choice: A conceptual framework and supporting evidence. Journal of Experimental Psychology: General, 143, 163-181. https://doi.org/10.1037/a0030831
Southward, M. W., Altenburger, E. M., Moss, S. A., Cregg, D. R., \& Cheavens, J. S. (2018). Flexible, Yet Firm: A Model of Healthy Emotion Regulation. Journal of Social and Clinical Psychology, 37(4), 231-251. https://doi.org/10.1521/jscp.2018.37.4.231

Southward, M. W., \& Cheavens, J. S. (2020). More (of the right strategies) is better: Disaggregating the naturalistic between- and within-person structure and effects of emotion regulation strategies. Cognition and Emotion 34 ,

1729-1736. https://doi.org/10.1080/02699931.2020.1797637

Stok, F. M., de Ridder, D. T. D., de Vet, E., Nureeva, L., Luszczynska, A., Wardle, J., Gaspar, T., \& de Wit, J. B. F. (2016). Hungry for an intervention? Adolescents' ratings of acceptability of eating-related intervention strategies. BMC Public Health, 16, 5. https://doi.org/10.1186/s12889-015-2665-6

Tamir, M. (2021). Effortful Emotion Regulation as a Unique Form of Cybernetic Control. Perspectives on Psychological Science, 16, 94-117. https://doi.org/10.1177/1745691620922199

Tangney, J. P., Baumeister, R. F., \& Boone, A. L. (2004). High self-control predicts good adjustment, less pathology, better grades, and interpersonal success. Journal of Personality, 72, 271-324. https://doi.org/10.1111/j.0022-3506.2004.00263.x

Troy, A. S., Shallcross, A. J., \& Mauss, I. B. (2013). A person-by-situation approach to emotion regulation: Cognitive reappraisal can either help or hurt, depending on the context. Psychological Science, 24, 2505-2514. https://doi.org/10.1177/0956797613496434

Tsukayama, E., Duckworth, A. L., \& Kim, B. (2012). Resisting Everything except Temptation: Evidence and an Explanation for Domain-specific Impulsivity. European Journal of Personality, 26, 318-334. https://doi.org/10.1002/per.841

Werner, K. M., \& Gross, J. J. (in-preparation). Self-control: A polyregulation approach.

Werner, K. M., Inzlicht, M., \& Ford, B. Q. (2022). Whither inhibition? Current Directions in Psychological Science, 31, 333-339. https://doi.org/10.1177/09637214221095848

Werner, K. M., \& Milyavskaya, M. (2018). Motivation and self-regulation: The role of want-to motivation in the processes underlying selfregulation and self-control. Social and Personality Psychology Compass. https://doi.org/10.1111/spc3.12425

Werner, K. M., Wu, R., \& Friese, M. (2022). Strategy repertoire and goal attainment [Preprint]. PsyArXiv. https://doi.org/10.31234/osf.io/5uvxg

Wilkowski, B. M., \& Ferguson, E. L. (2016). The steps that can take us miles: Examining the short-term dynamics of long-term daily goal pursuit. Journal of Experimental Psychology: General, 145, 516-529. https://doi.org/10.1037/xge0000150

This pre-print was designed using the following template: Wiernik, B. M. (2019, October 11). Preprint templates. https://doi.org/10.17605/OSF.IO/HSV6A 